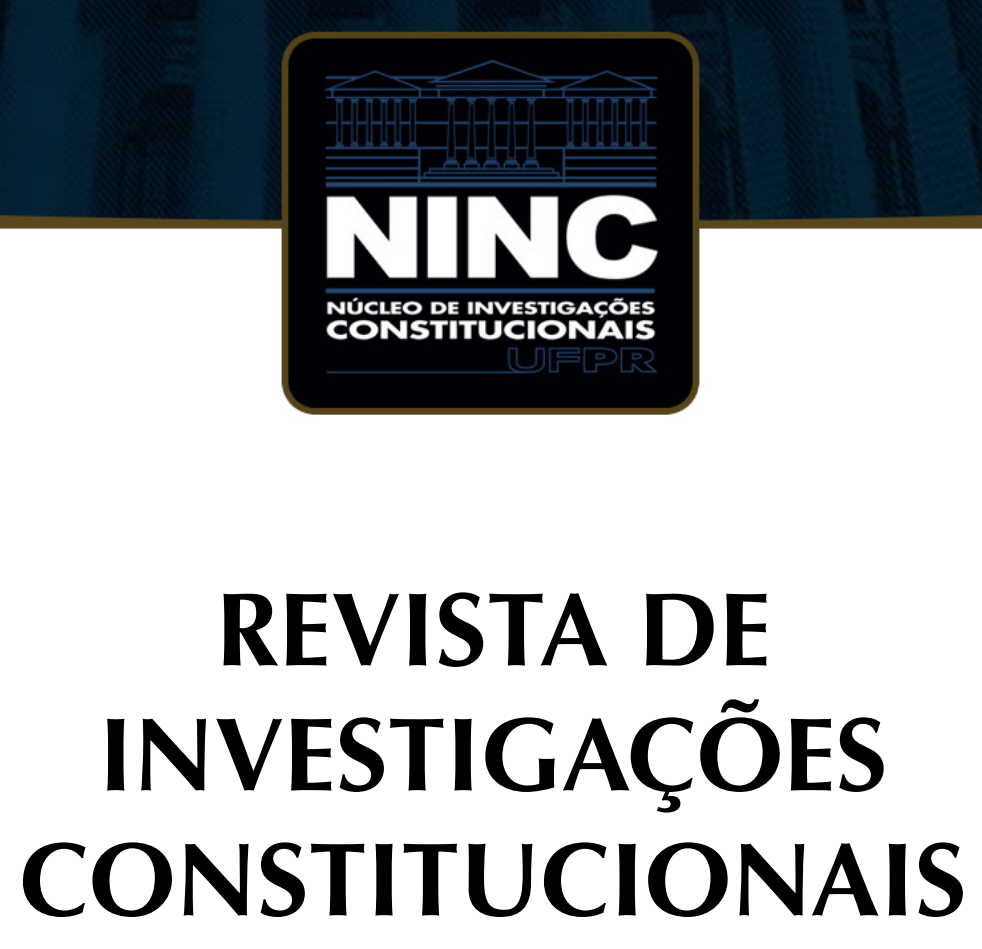

vol. 4 | n. 1 | janeiro/abril 2017 | ISSN 2359-5639 | Periodicidade quadrimestral Curitiba | Núcleo de Investigações Constitucionais da UFPR | www.ninc.com.br 


\title{
Los mecanismos de control constitucional: un análisis desde y para Cuba con especial referencia a la inconstitucionalidad por omisión
}

\section{The mechanisms of constitutional control: an analysis from and to Cuba with special reference to the unconstitutionality by omission}

\author{
RAUDIEL F. PEÑA BARRIOS* \\ Universidad de La Habana (Cuba) \\ rpbarrios88@gmail.com
} Recebido/Received: 18.11 .2016 / November 18th, 2016 Aprovado/Approved: 12.02.2017 / February 12th, 2017

Resumen

Este artículo pretende ofrecer algunas consideraciones sobre los instrumentos para el control de constitucionalidad. La temática, sin lugar a dudas de extraordinaria actualidad, sigue generando profundos análisis desde la óptica de varias Ciencias Sociales. En la experiencia cubana, caso de estudios sobre el cual recaerá el peso fundamental de este trabajo, cobra especial necesidad que se debata respecto a cómo perfeccionar los controles constitucionales existentes; considerando las características de nuestro sistema político y ordenamiento jurídico. Aún y cuando este tema ha sido abordado con amplitud por la doctrina nacional, un aspecto que se ha tratado muy poco es cómo controlar la constitucionalidad ante omisiones del legislador. Por tanto, y luego de exponer
Abstract

This article aims to offer some considerations on the instruments for judicial review. The subject, undoubtedly extraordinary today, continues to generate depth analysis from the perspective of several Social Sciences. In the Cuban experience, case studies on which will rest the fundamental importance of this labor is especially need to be discussed on how to improve existing constitutional controls; considering the characteristics of our political system and juristic law. Even if this issue has been addressed extensively by the national doctrine, an aspect that has been addressed is how little control the constitutionality before omissions of the legislature. Therefore, and after explaining some overall questions of constitutional control models and their characteristics and other relevant aspects, theoretically we will address

Como citar esse artigo/How to cite this article: BARRIOS, Raudiel F. Peña. Los mecanismos de control de constitucional: un análisis desde y para Cuba con especial referencia a la inconstitucionalidad por omisión. Revista de Investigações Constitucionais, Curitiba, vol. 4, n. 1, p. 87-108, jan./abr. 2017. DOI: 10.5380/rinc.v4i1.49303.

* Profesor de Derecho Constitucional en el Departamento de Estudios Jurídicos Básicos de la Facultad de Derecho de la Universidad de La Habana (La Habana, Cuba). Maestrante en Derecho Constitucional y Administrativo en la Universidad de La Habana. Licenciado en Derecho por la Universidad de La Habana. Asesor jurídico empresarial. E-mail: rpbarrios88@gmail.com. 
algunas cuestiones general sobre los modelos de control constitucional, así como sus características y otros aspectos relevantes, abordaremos teóricamente la inconstitucionalidad por omisión. Finalmente, valoraremos la efectividad de los controles constitucionales en Cuba ante la inactividad del órgano legislativo en el cumplimiento del deber de legislar, por remisiones a leyes de desarrollo que hace el texto constitucional.

Palabras-claves: Constitución; control de constitucionalidad; inconstitucionalidad; omisión; Cuba. the unconstitutionality by omission. Finally, we assess the effectiveness of constitutional controls in Cuba, to the inactivity of the legislature in the line of duty to legislate for referrals to developmental laws making constitutional text.

Keywords: Constitution; judicial review; unconstitutionality; omission; Cuba.

\section{SUMARIO}

1. A modo de presentación. Breves apuntes sobre la noción de control y su vínculo con la Constitución.

2. Modelos de Control. Características, condiciones estructurales, principios. Puntos a favor y en contra.

3. La inconstitucionalidad por omisión. Sucinta aproximación teórico-doctrinal. 4. Control constitucional en Cuba. Valoraciones sobre su eficacia y propuestas al respecto. Observación especial sobre la inconstitucionalidad por omisión. 4.1. ¿Qué ha pasado con las omisiones de legislador? 5. A modo de conclusiones. 6. Referencias.

A todo principio de Derecho acompaña la seguridad de que el Estado se obliga a sí mismo a cumplirlo, lo cual es una garantía para los sometidos al Derecho.

\section{A MODO DE PRESENTACIÓN. BREVES APUNTES SOBRE LA NO- CIÓN DE CONTROL Y SU VÍNCULO CON LA CONSTITUCIÓN}

Dentro de los debates actuales que se desarrollan en el área del Derecho Constitucional y la Teoría Política en general, el control de constitucionalidad sigue teniendo un peso importante. Por qué resultan necesarios los mecanismos de control; para qué sirven; qué modelo resulta más eficaz; en dónde descansa la legitimidad de las instituciones que intervienen en cada modelo; siguen siendo interrogantes que hoy suscitan amplios análisis teóricos en muchos estudiosos de estas cuestiones.

Un primer acercamiento a esta temática nos obliga a tomar postura respecto a qué debe entenderse por control. En este sentido, asumimos que se trata de un mecanismo de defensa de la Constitución, y por tanto propenderá a la verificación de que las actuaciones de los órganos estatales y sus funcionarios no vulneren la supremacía constitucional, ni los derechos reconocidos por la misma. Aquel no puede ser visto como una restricción o anulación de los derechos individuales o colectivos ni de las 
facultades de determinados órganos ${ }^{1}$. En todo caso debe ser entendido como parte necesaria del funcionamiento de los aparatos de poder del Estado, lo cuales deben cumplir siempre en su actuar con los postulados constitucionales.

De lo que se trata es de establecer las vías y procedimientos mediante los cuales se verifique y, de ser el caso, se anule cualquier disposición normativa, acto de la administración o derivados del accionar político, emitidos sobre la base de la extralimitación en las competencias de los órganos estatales. Así se tributa a la eficacia y validez de las disposiciones normativas; y más importante aún a la legitimidad del sistema político. Por otra parte, se contribuye con la base axiológica del ordenamiento jurídico, pues se establecen reglas del juego encaminadas a acatar los Principios de Supremacía Constitucional y Jerarquía Normativa. Todo ello mientras se vigilan la armonía, coherencia y plenitud del propio ordenamiento.

En la actualidad existe una franca tendencia mundial que conlleva la constitucionalización del ordenamiento jurídico, a partir de aplicar de forma directa la Constitución por parte de los tribunales. La defensa de los derechos recogidos en aquella opera como una garantía material, pues se le otorga significado a determinados preceptos constitucionales que cobran especial valor en el orden jurídico, como pueden ser los conceptos de justicia y seguridad ciudadana.

Ahora bien, sobre la determinación de qué modelo de control constitucional adoptar inciden diversas variables sobre todo de índole política, filosófica e ideológica. La más importante de ellas es la concepción que se tenga respecto al poder.

Luego de las revoluciones burguesas de mediados del siglo XVIII y con el auge de la Tripartición de Poderes, la cual mantiene una impronta trascendente en el constitucionalismo moderno, quedó fijada una concepción que establecía la necesidad de controles entre cada uno de los poderes constituidos. Esta es en nuestra opinión el principal legado de tal teoría: lo imperioso de controlar el ejercicio del poder como fundamento de la democracia. ${ }^{2}$

Más allá de que se pueda estar de acuerdo o no con sus postulados, y aun considerando las características de cualquier sistema político contemporáneo; no cabe dudas que el control sobre la actuación estatal resulta de extrema importancia. Bien se acepte la idea de que el poder del Estado es divisible y se distribuye entre cada uno de los órganos constituidos para el ejercicio del mismo; o bien se deseche aquella al considerarlo como indivisible y solo aceptar la diferenciación de funciones entre dichos

\footnotetext{
1 PRIETO, Marta. El control como instrumento de aseguramiento de derechos y de la continuidad del diseño. Conferencia magistral en VIII Encuentro de la Sociedad de Derecho Constitucional y Administrativo. La Habana: abril 2 de 2008.

2 Sobre varios elementos de la teoría del control constitucional, en particular la importancia de los controles de constitucionalidad en un Estado democrático, ARAGÓN, Manuel. Constitución, democracia y control. México D.F.: Instituto de Investigaciones Jurídicas de la Universidad Nacional Autónoma de México (UNAM), 2002. p. 81-208.
} 
órganos; no cabe duda que en ambos casos resultan imprescindibles los mecanismos de control.

\section{MODELOS DE CONTROL. CARACTERÍSTICAS, CONDICIONES ES- TRUCTURALES, PRINCIPIOS. PUNTOS A FAVOR Y EN CONTRA}

La propia evolución del constitucionalismo como fenómeno político-jurídico y del Derecho Constitucional como ciencia, han llevado a implementar múltiples formas y diferentes momentos para el ejercicio del control. En esencia existen dos modelos que podríamos denominar clásicos de control de constitucionalidad. El primero de ellos es el modelo difuso, también denominado americano, y el otro es el concentrado.

Ante de continuar nuestro análisis sobre esta temática, vale recordar que de acuerdo con Fix-Zamudio pudiera hablarse de un tercer modelo de justicia constitucional denominado socialista, teniendo en cuenta la experiencia desarrollada en la URSS y Cuba, donde se coloca en manos del órgano legislativo la tutela de la supremacía constitucional $^{3}$. Acerca de este tema solo decir que es un juicio que no comparto. El hecho de que se encargue a tales órganos la tarea del control constitucional, tanto con respecto a las disposiciones normativas emitidas por ellos (leyes) como otras de inferior jerarquía, no es más que una adaptación del control político, y además previo, a las características del sistema político de esos dos países. Recuérdese que se trata, tanto en el modelo soviético mientras existió como en el cubano actual, de sistemas monopartidistas y donde el órgano legislativo es conformado sobre la base de principios diferentes a los de sistemas electorales competitivos.

Volviendo sobre los modelos clásicos, podemos afirmar que el control difuso surge con la célebre sentencia de 24 de febrero de 1803, dictada por la Corte Suprema de los Estados Unidos de América, en el caso Marbury versus Madison.

Se trata de un modelo que tiene diferentes repercusiones en dependencia del sistema jurídico que se trate, sobre todo de la jerarquía de las fuentes del Derecho. Partiendo de que el cuestionamiento sobre la constitucionalidad de la disposición normativa es con respecto a un caso en concreto, la sentencia sólo posee efectos respecto a este. Por tanto, se deja de aplicar dicha normativa pero nunca podrá el órgano judicial declarar la derogación o nulidad de la misma. De esta forma en un Estado del sistema de derecho romano-germano-francés, no se declara la inconstitucionalidad de la disposición en sí misma, sino que esta se deja de aplicar. En el caso del Common Law, y teniendo en cuenta el papel como fuente de Derecho del precedente judicial, una vez que se dicta una sentencia esta se convierte en precedente de obligatorio

\footnotetext{
3 SIMÓN, Liana. El control de constitucionalidad de las leyes en Cuba: el reto de su judicialización. En: MATILLA, Andry; FERRER Eduardo (Coords.). Escritos sobre Derecho Procesal Constitucional. La Habana: Unión Nacional de Juristas de Cuba, 2012. p. 268. Nota al pie n. 2.
} 
cumplimiento para todos los tribunales inferiores. Además, tanto en un sistema como en otro la sentencia tiene efectos retroactivos y fuerza de cosa juzgada.

No obstante todo lo anteriormente dicho, quiero destacar que aunque los tribunales solo dejen de aplicar la disposición normativa a una situación específica, en la medida que esa inaplicación vaya reiterándose en el tiempo existe un mensaje del aparato judicial al órgano legislativo. Ese mensaje es muy preciso: dentro del ordenamiento jurídico hay una ley (u otra disposición de cualquier rango) que no es aplicable pues viola derechos constitucionalmente reconocidos, y debe ser extraída de aquel. La recepción de dicho mensaje por parte del aparato legislativo dependerá de las relaciones de poder entre los diferentes órganos estatales.

Este modelo es fuertemente criticado debido a la concentración de poder que se produce en la estructura judicial, alegándose que los jueces pueden sobreponerse al poder legislativo distorsionando, más que interpretando, la Constitución de acuerdo a sus posiciones políticas ${ }^{4}$. Nos parece atinado señalar que esta postura, si bien tiene una sólida base, puede ser aplicado a otros modelos de control, incluso aquellos de tipo mixto.

Por otra parte, el sistema concentrado de constitucionalidad ubica el control en un órgano especial, de carácter político, que tiene la facultad de dejar sin efecto la normativa inconstitucional. Dado a conocer con la Constitución de Austria de 1919 y fruto de la obra teórica de Hans Kelsen, esta vez se trata de un órgano judicial cuya declaración de inconstitucionalidad sí tiene efectos inmediatos sobre la permanencia de determinada normativa en el ordenamiento jurídico. La existencia de un Tribunal Constitucional implica que todo conflicto surgido en el marco de la Constitución, bien entre órganos de poder o de ciudadanos contra dichos órganos, debe resolverlo un tercero independiente e imparcial al conflicto5.

Se le conoce como concentrado porque un solo órgano ejerce el control de constitucionalidad (en muchos casos en forma exclusiva y excluyente respecto de otros órganos del Estado). Además, se le cataloga como abstracto porque analiza la disposición normativa cuestionada en su relación con la Constitución, no sobre la base de un caso concreto, sino teniendo en cuenta razones de estricto Derecho que vician de inconstitucionalidad a la norma de menor jerarquía. También tiene efectos derogatorios pues aquella dejará de tener vigencia. ${ }^{6}$

\footnotetext{
4 FERNÁNDEZ, Julio. Los modelos de control constitucional y la perspectiva de Cuba hoy. En: PÉREZ, Lissette; PRIETO, Marta (Comps.). Temas de derecho constitucional cubano. La Habana: Ed. Félix Varela, 2004. p. 355.

5 KELSEN, Hans. Teoría pura del Derecho. Madrid: Ed. Tecnos, 1995. p. 52.

6 BLUME, E. La reforma del Tribunal Constitucional peruano. In: VEGA GÓMEZ, Juan; CORZO SOSA, Egar (Coords.). Tribunales y Justicia Constitucional: Memorias del VII Congreso Iberoamericano de Derecho Constitucional. México D.F.: Instituto de Investigaciones Jurídicas de la UNAM, 2002. p. 39.
} 
La crítica fundamental que se le hace es que va contra la sacrosanta Tripartición de Poderes, pues el tribunal político de control de constitucionalidad se convierte en un cuarto poder, que se va por encima e impone decisiones al legislativo y al gobierno. También se le cuestiona por su potencial subordinación fáctica al poder ejecutivo en el rejuego de intereses que se puede presentar en un sistema político determinado?. Quizás el ejemplo más actual y elocuente de esta situación sea la dinámica en la que ha recaído la Sala Constitucional del Tribunal Supremo de Justicia (TSJ) de Venezuela. Este órgano judicial ha adoptado determinadas fallos contra la Asamblea Nacional, controlada por fuerzas políticas opuestas al ejecutivo, realizando cuestionables interpretaciones de la carta magna de ese país ${ }^{8}$. Empleando un lenguaje figurado pudiera afirmarse que se está librando una batalla política (ejecutivo v/s parlamento) con armas propiamente jurídicas, pero que en ningún caso pueden descargarse de su contenido político.

Además de las críticas anteriores hoy lo que más se cuestiona es la legitimidad democrática de estos tribunales. Este tema parte de la llevada y traída polémica respecto al hecho de que el órgano legislativo está integrado por representantes populares, que han sido refrendados como tales por sufragio directo; y por tanto un grupo de jueces no electos de esta forma pueden invalidar una ley emanada de aquel órgano9.

Sobre este particular considero que debemos dejar establecidas algunas premisas elementales. En primer lugar, la única fuente de legitimidad en cualquier sistema político no es la elección popular, por lo que puede decirse que la de los tribunales constitucionales descansa en el aspecto técnico. Esto último considerando el riguroso procedimiento que debe caracterizar la preparación, selección y nombramiento de los miembros de esos órganos. No obstante, nada es impedimento para establecer un mecanismo de elección popular de esos magistrados. Sirva de ejemplo la elección por sufragio universal de los miembros del Tribunal Constitucional Plurinacional, de acuerdo a lo establecido por el artículo 198 de la Constitución boliviana de 200910. Con este proceder se democratiza la conformación del órgano centralizado y especializado de justicia constitucional.

\footnotetext{
7 VALDÉS, E.; PARDO, O. Los sistemas de control constitucional frente a los derechos fundamentales en Colombia, Cuba y España. Revista UIS-Humanidades, Bucaramanga vol. 28, n. 1, ene./jun. 1999. p. 94.

8 BREWER, Allan. La elección popular indirecta de altos funcionarios del Estado en Venezuela y su violación por el Estado autoritario: el golpe de Estado de diciembre de 2014 dado con las inconstitucionales designaciones de los titulares de las ramas del Poder Público. Revista de Investigações Constitucionais, Curitiba, vol. 2, n. 2, p. 63-92, maio/ago. 2015.

9 FIX, Héctor. Breves reflexiones sobre la naturaleza, estructura y funciones de los organismos jurisdiccionales especializados en la resolución de procesos constitucionales. In: VEGA GÓMEZ, Juan; CORZO SOSA, Egar (Coords.). Tribunales y Justicia Constitucional: Memorias del VII Congreso Iberoamericano de Derecho Constitucional. México D.F.: Instituto de Investigaciones Jurídicas de la UNAM, 2002. p. 218.

10 VICIANO, Roberto; MARTíNEZ, Rubén. Fundamentos teóricos del nuevo constitucionalismo latinoamericano. En: VICIANO, Roberto (Edit.). Estudios sobre el nuevo Constitucionalismo Latinoamericano. Valencia: Ed. Tirant Lo Blanch, España, 2012. p. 42.
} 
Como lógico proceso de desarrollo de estos dos modelos, así como de la evolución propia de las experiencias nacionales, han surgido el llamado sistema mixto y el múltiple. En los países en los cuales existe un sistema mixto o integral de control de la constitucionalidad, dado el funcionamiento paralelo del método de control difuso con el control concentrado de las leyes, este último siempre tiene carácter principal pues sobre él conoce un órgano especializado en materia constitucional, cuando se ejerce una acción de inconstitucionalidad ante el mismo'11. Mientras, en el modelo múltiple cada tribunal de justicia se encuentra obligado a aplicar la Constitución ante cualquier norma o acto que la transgreda, sin derogar la disposición vulneradora. Para esto último se crea una jurisdicción constitucional (encarnada en un Tribunal de Constitucionalidad), que sí tiene la facultad de declarar la inconstitucionalidad para todos los casos mediante la derogación de la disposición normativa o acto que se trate. 12

La diferencia fundamental entre estos dos modelos radica en que el sistema mixto combina a la vez y en paralelo el control difuso y el concentrado. El control de constitucionalidad descansa en un ente ubicado dentro del poder judicial, que es por regla general el órgano supremo del mismo, o una sala especializada de su seno ${ }^{13}$. En este caso la declaración de inconstitucionalidad es a instancia de parte, en un caso concreto, pero alcanza la nulidad o derogación total del acto o norma impugnada. Por otro lado, en el múltiple coexisten de forma yuxtapuesta el concentrado y el difuso, de acuerdo a las características expuestas supra, pero siempre determinado en su esencia por el establecimiento de una jurisdicción constitucional fuera de la estructura judicial común ${ }^{14}$.

Todos estos modelos representan sistemas jurisdiccionales de control, pues hay un órgano o varios órganos del aparato judicial controlando. Al respecto vale la pena hacer algunas reflexiones, en aras de profundizar sobre la trascendencia del control de constitucionalidad efectuado por los tribunales.

En los sistemas políticos contemporáneos pueden darse situaciones donde se aprueben disposiciones normativas que entren en contraposición por motivos políticos, por la existencia de diversos actores (ejecutivo y legislativo) generando Derecho.

\footnotetext{
11 FERRER, Eduardo et al. (Coords.). Diccionario de Derecho Procesal Constitucional y Convencional. Tomos I y II. México D.F.: Instituto de Investigaciones Jurídicas de la UNAM, 2014. p. 233.

12 Sobre esta clasificación vid. RODRÍGUEZ, Yumil. Algunas consideraciones sobre la supremacía de la Constitución y el control de constitucionalidad como medio de hacerla efectiva. MATILLA, Andry; FERRER Eduardo (Coords.). Escritos sobre Derecho Procesal Constitucional. La Habana: Unión Nacional de Juristas de Cuba, 2012. p. 280 y 281.

13 Por ejemplo, en el caso de Brasil esta atribución recae en el Tribunal Supremo mientras que en México y Venezuela se ubica en una Sala Constitucional dentro del máximo órgano judicial. Vid. FERRER. Op. cit., p. 232. 14 Este sistema es propio de países como Chile, Ecuador, Guatemala, Perú, Bolivia y Colombia. Vid. FERNÁNDEZ, Julio. Los modelos de control constitucional y la perspectiva de Cuba hoy. En: PÉREZ, Lissette; PRIETO, Marta (Comps.). Temas de derecho constitucional cubano. La Habana: Ed. Félix Varela, 2004. p. 353 y 354 ; y ARMENGOL, Carlos. El Derecho Constitucional del Siglo XXI en Latinoamérica: Un cambio de paradigma. En: VICIANO, Roberto (Edit.). Estudios sobre el nuevo Constitucionalismo Latinoamericano. Valencia: Ed. Tirant Lo Blanch, España, 2012. p. 58.
} 
Por tanto, se produce la necesidad de armonizar el contenido de las mismas, y en esta situación el aparato judicial cobra especial relevancia como mecanismo de control ante los reclamos de la ciudadanía por la observancia de sus derechos. Puede afirmarse que la intervención de los tribunales contribuye a favorecer la defensa del Principio de Seguridad Jurídica, desde su imparcialidad con respecto al objeto del proceso.

Además, otro aspecto favorable de los controles jurisdiccionales es que los mismos deben vertebrase, al menos teóricamente, en virtud del debido proceso. Este no es más que el proceso lógicamente concebido en estricto apego a los principios ínsitos al ordenamiento jurídico, establecidos desde el propio texto constitucional ${ }^{15}$. El rasgo más evidente en este sentido es la oposición de la justicia constitucional a la cosa juzgada material, pues se revisa la constitucionalidad de una decisión judicial. Lo anterior está en consonancia con la tutela judicial efectiva, que hoy es asumida como un derecho subjetivo público ${ }^{16}$ que consiste en obtener una resolución judicial motivada y congruente, que se pronuncie sobre el fondo de las pretensiones deducidas, siempre que concurran los presupuestos procesales necesarios para ello. De acuerdo con su contenido permite asegurar el debate y la contradicción sobre la base acceder a tribunales independientes e imparciales; con el fin de plantear una pretensión o defenderse de ella; a través de un proceso justo y razonable en el que se respeten los derechos que corresponden a las partes, entre otros aspectos.

Pero la práctica también ha colocado la actividad de controlar en el marco de lo político. De esta manera los mismos órganos que dictan las leyes, serán quienes establezcan si estas contradicen o no a la Constitución. El señalamiento elemental a este sistema es que el órgano legislativo actúa como juez y parte, pues elabora las leyes y realiza el control de su constitucionalidad.

Según el momento en que se controla este puede ser previo: cuando implica que las normas ordinarias sean sometidas a un proceso de revisión con anterioridad a su promulgación. En realidad lo que se revisa son proyectos de ley, por parte de un órgano político o judicial. Así se busca lograr que la ley, como colofón de un acto normativo, nazca con un voto de constitucionalidad. Sirvan como ejemplos de este control previo el realizado en Francia por el Consejo Constitucional17 o los dictámenes de constitucionalidad de los tribunales supremos en otros países. También puede realizarse un control posterior, que es el que se ejerce sobre las normas ya vigentes, a instancia de parte ante un órgano judicial (bien ordinario o especial), e incluso de oficio.

\footnotetext{
15 Sobre esta categoría vid. Ferrer et al. (Coords.). Op. cit., p. 297-299; y ALVARADO, Adolfo. El debido proceso. En: UNAM. Justicia y Sociedad. México D.F.: Instituto de Investigaciones Jurídicas de la UNAM, 1994. p. 561.

16 Acerca del reconocimiento actual de esta categoría como derecho subjetivo público vid. FERRER et al. (Coords.). Op. cit., Tomo II, p. 809.

17 PERAZA, José. Derecho Constitucional General y Comparado. La Habana: Ed. Félix Varela, 2002. p. 92.
} 


\section{LA INCONSTITUCIONALIDAD POR OMISIÓN. SUCINTA APROXI- MACIÓN TEÓRICO-DOCTRINAL}

Sin pretender ahondar en el debate, por demás a nuestro criterio ya superado, sobre la existencia o no de la inconstitucionalidad por omisión 18 , e incluso sobre si esta puede abarcar solo al legislativo ${ }^{19}$ y no al ejecutivo; expondremos algunas ideas al respecto. Una sencilla definición acerca de la inconstitucionalidad de este tipo es la falta de desarrollo, durante un tiempo excesivamente largo, de aquellas normas constitucionales de obligatorio y concreto impulso, de forma tal que se impide su eficaz aplicación. Se verifica en los casos en que no se han practicado los actos legislativos o ejecutivos requeridos, para volver plenamente aplicables normas constitucionales 20 .

Se trata del incumplimiento por parte de los poderes constituidos de un mandato constitucional positivo que les obliga a crear una norma legal para desarrollar determinados preceptos ${ }^{21}$. Somos de la opinión de que tanto el órgano legislativo como ejecutivo puede incurrir en inconstitucionalidad por omisión, siempre que exista el incumplimiento de una obligación que le viene impuesta por mandato expreso de una norma constitucional22. Claro está que la práctica política-constitucional por lo general ha colocado en manos del legislativo el desarrollo de las normas superiores. Sin embargo, nada obsta para que estas remisiones recaigan en el ejecutivo, y que este instrumente disposiciones constitucionales mediante el uso, por ejemplo, de decretos presidenciales, decretos-ley, decretos de necesidad y urgencia, etcétera.

La consideración de la carta magna como disposición normativa superior del ordenamiento jurídico, y no como una mera exposición de principios programáticos, es el presupuesto sobre el cual se vertebra este instituto. En consonancia, resulta de estricta

\footnotetext{
18 Aunque progresivamente se ha ido imponiendo la opinión de que existe la inconstitucionalidad por omisión, cabe resaltar que a inicios de siglo aún era negada por algunos autores. Al respecto y solo a modo de ejemplo vid. RUIZ, Ricardo. Crítica a la llamada inconstitucionalidad por omisión. Revista Iberoamericana de Derecho Procesal Constitucional, Ciudad de México, n. 2, jul./dic. 2004; y PÉREZ, Javier. Inconstitucionalidad por Omisión. Temas Básicos de Derecho Constitucional. Vol. 3. Madrid: Ed. Civitas, 2001. p. 66-68.

19 LEAL, Salvador. Inconstitucionalidad por omisión. Revista Cuestiones Políticas, Maracaibo, vol. 18, n. 18, p. 53-67, jun. 2002. p. 63; y ROJAS, Sandra. Inconstitucionalidad por omisión en Colombia. Revista Estudios de Derecho, Bogotá, año LXII, vol. LIX, n.133-134, jul./dic. 2000. p. 99 y ss.; entre otros. Estos autores defienden la idea de que solo el legislativo puede incurrir en omisiones vulneradoras de la Constitución.

20 SILVA, Alfonso da. Aplicabilidad de las normas constitucionales. México D.F.: Instituto de Investigaciones Jurídicas de la UNAM, 2003. p. 153. Este tratadista sostiene el criterio de que el ejecutivo también puede incurrir en inconstitucionalidad por omisión.

21 NOGUERA, Albert. Los derechos sociales en las nuevas constituciones latinoamericanas. Valencia: Ed. Tirant lo Blanch, 2010. p. 84.

22 Sobre nuestra posición vid. MIRANDA, Jorge. Manual de direito constitucional. Vol. II. Coímbra: Ed. Coímbra, 1993. p. 338; BIDART, Germán J. La justicia constitucional y la inconstitucionalidad por omisión. Anuario Jurídico UNAM, México D.F., v. 6, p. 9-18, 1979. p. 9 y ss; y RODRIGUES, Márcia. Inconstitucionalidade por omissão. Revista da Procuradoria Geral do Estado de São Paulo, São Paulo, vol. 18, n. 30, jul./dez. 1988. p. 42.
} 
observancia el tratamiento de aquellos contenidos que remitan a las correspondientes leyes especiales.

El llamado reconocimiento del carácter normativo de la Constitución deriva en la aplicabilidad directa de los preceptos superiores, de ahí que de toda norma constitucional pueda derivarse un contenido de eficacia directa. La Constitución no es referencia normativa, ni mera norma de acompañamiento. Como norma jurídica al fin es autoaplicable, sobre todo si faltan leyes que la desarrollen.

Puede afirmarse que existe un derecho subjetivo público de los ciudadanos a la actividad legislativa, imprescindible para la plena eficacia en el ejercicio y protección de sus derechos. Además, el Principio de Supremacía Constitucional, sustento del constitucionalismo contemporáneo, supone necesariamente el control y la sanción consecuente de las infracciones a la Constitución, las que pueden originarse tanto en acciones positivas que violen la ley fundamental como en omisiones que contraríen un precepto legal23. El ordenamiento jurídico no puede prescindir de mecanismos de sanción ante las infracciones de la norma suprema, pues esto pondría en tela de juicio la preeminencia que sobre las restantes normas e instituciones ostenta la misma.

Varios autores colocan a Wessel como precursor de este concepto ${ }^{24}$, quien planteó la posibilidad de que podían vulnerarse derechos individuales a causa de un no hacer del legislador. De este propio autor procede la clasificación25 que distingue entre omisiones absolutas y relativas. Se refiere a las absolutas (también llamadas totales o materiales) como la carencia de cualquier disposición de desarrollo legislativo del precepto constitucional. Las relativas (conocidas igualmente por parciales o formales) ocurren debido a que de la actividad del legislador ha emanado una ley que disciplina sólo algunas relaciones y no otras aun tratándose de supuestos análogos, con la consiguiente lesión del Principio de Igualdad. En general se habla de omisiones relativas para referirse a los casos en que la regulación dada por el legislador es incompleta, defectuosa o no idónea para cubrir los hipotéticos supuestos que abarca la norma. La trascendencia de esta clasificación estriba en los efectos derivados del control jurisdiccional: la omisión absoluta provoca la imposibilidad de cualquier intervención correctiva del órgano judicial, no sucediendo así en los supuestos de omisión relativa en donde se abren espacios para la actuación del intérprete de la norma incompleta o defectuosa.

23 GARZÓN, Edgard F. La inconstitucionalidad por omisión: una revisión jurídica. Revista Dixi 20, Bogotá, vol. 16, n. 20, p. 29-36, dic. 2014. p. 30.

24 AHUMADA, María. El control de constitucionalidad de las omisiones legislativas. Revista del Centro de Estudios Constitucionales, Madrid, n. 8, p. 169-194, ene./abr. 1991. p. 172; y FERNÁNDEZ, Julio A. Aproximación a la constitucionalidad por omisión. En: CARBONELL, Miguel (Coord.). En busca de las normas ausentes. Ensayos sobre la inconstitucionalidad por omisión. México D.F.: Instituto de Investigaciones Jurídicas de la UNAM, 2003. p. 58.

25 Sobre otros criterios de clasificación vid. FERNÁNDEZ, Julio A. Aproximación a la constitucionalidad por omisión. En: CARBONELL, Miguel (Coord.). En busca de las normas ausentes. Ensayos sobre la inconstitucionalidad por omisión. México D.F.: Instituto de Investigaciones Jurídicas de la UNAM, 2003. p. 57-64. 
Otro autor de obligada referencia al abordar cuestiones constitucionales como Kelsen, concibió la posibilidad que la carta magna fuera quebrantada por un no hacer del legislador. Aquel planteó que vulnerar la Constitución significa la ocurrencia de un hecho que la contradice, sea por acción u omisión. Esto último se da solo cuando se trata del incumplimiento de una obligación, y no por una falta de reconocimiento de un derecho concedido por un órgano de la Constitución. En tal sentido, defiende la idea de que los postulados de la norma suprema que establecen órdenes de legislar, es decir la obligatoriedad de dotar de validez jurídica los preceptos constitucionales, deben ser desarrollados de forma expedita. Así y mediante la difusión de normas inferiores que desarrollen las superiores, el ordenamiento jurídico se integra y se reproduce a partir de la concatenación piramidal desde una norma general a una particular. 26

Por su parte, Karl Loewebstein sostuvo la idea de que la inercia de órganos constituidos en el complemento de la Constitución, representa uno de los más graves aspectos de lo que llamó patología constitucional. En su opinión tal escenario refleja un inaceptable desprecio a la autoridad suprema de la Ley Fundamental del Estado. ${ }^{27}$

Para que exista inconstitucionalidad por omisión deben reunirse dos requisitos, a saber: que la Constitución establezca un deber concreto de actuar del legislativo o ejecutivo; y que el tiempo transcurrido para el cumplimiento de aquel no sea razonable. Ninguna omisión puede describirse en abstracto y para concretizarla es necesario examinar en el caso puntual, el tiempo en el cual debió ser expedida la ley y la necesidad de producción de la misma para mantener el orden constitucional28. Sobre este último elemento solo añadir que la razonabilidad o no del tiempo de demora es un criterio eminentemente subjetivo, pero que pudiera verificarse a partir de las prioridades en materia legislativa y ejecutiva, cuando las mismas no toman en cuenta lo necesario de complementar la Constitución. Otro elemento a considerar es la ausencia de consenso político para aprobar la norma complementaria, lo cual también incide en el criterio de temporalidad acerca de su no adopción.

Ante la pasividad del legislador la única herramienta es accionar en sede judicial con el objetivo de compulsar al cumplimiento de la obligación impuesta por la lex superior. Los remedios pueden ser variados en dependencia del contexto, aunque por excelencia se ha empleado la llamada acción de inconstitucionalidad, y resulta obvio que sus características y efectos estarán vinculados al modelo de control jurisdiccional que se aplique en cada país ${ }^{29}$. Con tal intervención se pretende que los tribunales presionen

\footnotetext{
26 KELSEN, Hans. Teoría pura del Derecho. Madrid: Ed. Tecnos, 1995. p. 3.

27 LOEWENSTEIN, Karl. Teoría de la Constitución. Barcelona: Ed. Ariel, 1982. p. 222.

28 ARENAS, Marcela. Inconstitucionalidad por omisión legislativa. Contexto colombiano. Revista Diálogos de Derecho y Política, Bogotá, año 6, n. 13, p. 5-24, ene./abr. 2014. p. 11 y ss.

29 Acerca de algunos instrumentos empleados por los tribunales en el contexto latinoamericano para enfrentar la inconstitucionalidad por omisión vid. SAGÜÉS, Néstor. Problemas constitucionales en la solución de la
} 
para lograr la concreción legislativa sobre las disposiciones constitucionales, pues esta omisión daña contenidos esenciales del sistema político. No puede negarse el ejercicio de derechos asegurados constitucionalmente, pues tal quehacer es equivalente a la negación de la existencia del derecho mismo ${ }^{30}$.

\section{CONTROL CONSTITUCIONAL EN CUBA. VALORACIONES SOBRE SU EFICACIA Y PROPUESTAS AL RESPECTO. OBSERVACIÓN ES- PECIAL SOBRE LA INCONSTITUCIONALIDAD POR OMISIÓN}

Con la adopción del texto constitucional cubano de 1976, reformado en 1978, 1992, y 2002, se establecieron como principios de ordenación y funcionamiento del sistema político la Unidad de Poder y el Centralismo Democrático ${ }^{31}$. Bajo la influencia de la teoría y los regímenes políticos de Europa del Este, en especial el soviético, se vertebró una estructura estatal cuya base axiológica condicionó, no lo dude nadie, la noción sobre el control de constitucionalidad. Esto hizo que nuestro modelo no pueda ser encuadrado en ninguno de los vistos con anterioridad.

La tarea de controlar la constitucionalidad de nuestras leyes, decretos-leyes, decretos y demás disposiciones ha quedado en manos de la Asamblea Nacional del Poder Popular (ANPP), más allá del realizado por la Fiscalía General de la República vinculado con el aseguramiento de la legalidad. Asimismo, se realiza por la ANPP un control político y previo sobre las leyes emitidas por sí misma32; y uno político y posterior ${ }^{33}$ sobre las demás disposiciones antes señaladas. Esto supone que no hay fundamentación para que existan disposiciones que contravengan los postulados constitucionales, lo cual no es impedimento per se para que puedan existir incoherencias.

En el diseño cubano actual ha quedado excluido el aparato judicial del control de la supremacía constitucional, y se ha hecho depender el aseguramiento de los derechos constitucionales de procesos ordinarios; no de un proceso específico. Durante mucho tiempo se ha sostenido como fundamento de tal postura el reconocimiento de la Unidad de Poder como principio del sistema político. Sin embargo, como parte

\footnotetext{
inconstitucionalidad por omisión. Cuadernos Constitucionales de la Cátedra Fadrique Furió Ceriol, Rosario, n. 58-59, p. 253-264, 2007.

30 NOGUEIRA, Humberto. Consideraciones sobre las sentencias de los tribunales constitucionales y sus efectos en América del Sur. Revista lus et Praxis, Santiago de Chile, vol. 10, n. 1, p. 113-158, 2004. p. 154 y 155.

31 Sobre estos principios y su reconocimiento constitucional vid. DELGADO, Yanelys; DEL RÍO, Mirta A. La democracia socialista en la Constitución de 1976. En: MATILLA, Andry (Coord.). La Constitución cubana de 1976: cuarenta años de vigencia. La Habana: Ed. UNIJURIS, 2016. p. 53-66.

32 SIMÓN. Op. cit.. p. 275.

33 PÉREZ, Lissette; PRIETO, Marta. El control de la constitucionalidad de las leyes y otros actos. Sus formas en Estados Unidos y Cuba. En: PÉREZ, Lissette; PRIETO, Marta (Comps.). Temas de derecho constitucional cubano. La Habana: Ed. Félix Varela, 2004. p. 369 y ss.
} 
del propio diseño se estableció una diferenciación de funciones entre cada órgano del poder estatal.

Fue de esta manera que se reconoció constitucionalmente solo a la ANPP la potestad constituyente y legislativa. Al Consejo de Estado, órgano que representa a aquella entre cada uno de sus período de sesiones, se le facultó para dictar decretos-leyes. Además, se invistió al Consejo de Ministros, máximo órgano ejecutivo y administrativo y gobierno de la república, de la facultad de dictar decretos y otras disposiciones en cumplimiento de las leyes y para controlar su ejecución ${ }^{34}$. Por último cabe mencionar a los ministerios e institutos de subordinación nacional, los cuales emiten resoluciones y demás disposiciones en el marco de su competencia.

Mención aparte merece el hecho que desde el año 2010 el Presidente del Consejo de Estado, quien por mandato constitucional es Presidente del Consejo de Ministros 35 emite, en virtud de presidir este último órgano, decretos presidenciales. Este instrumento es típico de la forma de gobierno presidencialista, la que no se corresponde con la estructura de los órganos de poder cubanos ${ }^{36}$. Cabe resaltar que dichos decretos se publican, en principio, en la Gaceta Oficial de la República si así se establece en la propia norma legal. No obstante, se reconoce que cuando no sea el caso bastará con su notificación a las partes concernidas. Además, el Presidente del Consejo de Ministros puede adoptar decisiones sobre los asuntos ejecutivos, administrativos y de gobierno, cuando lo apremiante de la situación o el tema a solucionar lo exijan, sometiéndolas posteriormente a la consideración del Consejo de Ministros si así procediera.

A lo anteriormente expuesto hay que añadir que en Cuba no está reconocida por la Constitución la llamada Reserva de Ley, en el sentido de límites e impedimentos para el ejecutivo, por lo que no existen materias de exclusiva competencia de la ANPP. Esto ha significado el abandono de la reserva legal como garantía en sí, arguyéndose por algunos autores que la concepción unitaria sobre el poder destruye tal idea37. Las remisiones a leyes de desarrollo son previsiones para el legislativo en esferas que requieren tutela legal más allá de la constitucional. Los derechos constitucionales, por su significado y trascendencia para el individuo, deben ser desarrollados en una ley, y no

\footnotetext{
34 Acerca de los órganos superiores del poder estatal en Cuba, su composición, funciones, y demás aspectos vid. los artículos del 69 al 101 de la Constitución cubana. En: PÉREZ y PRIETO (Comps.). Selección legislativa de Derecho Constitucional Cubano. La Habana: Ed. Félix Varela, 2002. p. 33-42.

35 Artículo 74 en relación con el artículo 96 de la Constitución cubana. En: PÉREZ y PRIETO (Comps.). Op. cit. p. 33 y 40 .

36 VILLABELLA, Carlos. Las formas de gobierno en el mundo. Un estudio desde el derecho constitucional comparado de Europa, América Latina y el Caribe. Puebla: Instituto de Ciencias Jurídicas de la Universidad de Puebla, 2008. p. 73-82.

37 PRIETO, Marta Reflexiones en torno al carácter normativo de la Constitución. In: PÉREZ; PRIETO (Comps.). Temas de derecho constitucional cubano. La Habana: Ed. Félix Varela, 2004. p. 31.
} 
a través de normas de menor jerarquía, que resulten de órganos con una legitimidad indirecta o de segundo grado, como lo es el Consejo de Estado.

En la práctica tal coyuntura ha supuesto que solo la aprobación del presupuesto estatal ha quedado supeditada a una ley que cada año sanciona la ANPP, en virtud de lo establecido por el inciso e) del artículo 75 constitucional. Fuera de ese caso tanto el Consejo de Estado como el Consejo de Ministros han adoptado disposiciones sobre las más diversas cuestiones, incluidas muchas que inciden directa o indirectamente en los derechos de la ciudadanía. Considérese que el primero de aquellos órganos mediante la emisión de decretos-ley ha modificado infinidad de veces leyes, e incluso en innumerables ocasiones las ha derogado38.

Todo esto ha redundado en que coexistan varios entes interventores en la producción legislativa39 sin que se haya definido un catálogo de asuntos de exclusiva competencia de la ANPP. Por tanto, en este contexto pueden ocurrir situaciones de contradicción entre disposiciones de diferente jerarquía y de estas con respecto a la Constitución. De ahí que sostenga el criterio de que la Unidad de Poder no debe ser fundamento para excluir al sistema judicial de la defensa de la Constitución; ya sea de su supremacía o de los derechos reconocidos en ella 40 . Además, como un necesario refuerzo podría sumarse la conformación de una Sala Constitucional dentro del Tribunal Supremo Popular; espacio jurisdiccional donde acudirían los ciudadanos ante la vulneración de un derecho. Su establecimiento permitiría armonía normativa a través de juicios de validez precisos y un camino hacia la seguridad jurídica, tan necesaria en tiempos de perfeccionamiento de nuestra institucionalidad. También aseguraría la colocación en su justo lugar y grado del texto constitucional, a partir de convertirlo en norma de aplicación directa en las reclamaciones de derechos constitucionales, y garantía específica de estos últimos.

\footnotetext{
38 Sobre la jerarquía, efectos y demás cuestiones relacionada con los decretos-ley en el sistema de fuentes formales del Derecho en Cuba, vid. MATILLA, Andry. Comentarios sobre las fuentes del Derecho administrativo cubano (excepto el reglamento). In: Temas de Derecho Administrativo Cubano. La Habana: Ed. Félix Varela, 2006. p. 66-71.

39 Solo con la intención de mostrar lo complejo de este tema presentamos la siguiente estadística: Hasta finales de 2015 en Cuba se habían aprobado 326 decretos-leyes, 329 decretos, y desde 1987, fecha en la que las gacetas oficiales comenzaron a estar disponibles en formato digital, se han aprobado más de 20000 resoluciones. Vid. PROYECTO CUBA POSIBLE. Dossier: La Justicia en Cuba: pasado, presente y futuro. p. 20.

40 Desde el punto de vista histórico y comparativo cabe mencionar la experiencia de la extinta Yugoslavia, donde la Constitución de 1963 definía a la Asamblea Federal (máxima instancia legislativa) como el órgano supremo del poder. Sin embargo, la doctrina de la Unidad de Poder no fue obstáculo para el establecimiento de un órgano independiente cuya misión era el control de la constitucionalidad de la actividad jurídica desplegada por las otras autoridades. Se asignó a un Tribunal de Garantías Constitucionales el conocimiento del recurso de inconstitucionalidad de las leyes, y la sustanciación de cuestiones de incompatibilidad entre las leyes federales y las de cada república. Vid. FERNÁNDEZ, Serafín S. Cuba y el Control Constitucional en el Estado Socialista de Derecho: Reflexiones para su perfeccionamiento. En: MATILLA, Andry (Comp.). Estudios cubanos sobre control de constitucionalidad (1901-2008). México D.F.: Ed. Porrua, 2009. p. 391.
} 
Con este proceder se crearía un sistema mixto, donde por una parte los tribunales ordinarios emitirían constantes mensajes sobre la inconstitucionalidad de una ley u otra disposición, y su no aplicación a un caso concreto ante la obligación que les compete de aplicar directamente la Constitución. Esta labor que podríamos llamar de coordinación entre el aparato judicial y la ANPP recaería en el Consejo de Gobierno del Tribunal Supremo de Justicia (CGTSP), al cual le compete ejercer el control y la supervisión de la actividad jurisdiccional del sistema de tribunales, de acuerdo a lo dispuesto en el artículo 19.1 inciso f) de la Ley No82, Ley de los Tribunales Populares41. En paralelo existiría un órgano encargado de, si así fuera invocado, declarar la inconstitucionalidad de cualquier disposición y por ende su derogación con efecto erga omnes.

En adición, y más allá de tratar de exponer todos los criterios de clasificación sobre el control en Cuba, por demás tema ampliamente tratado donde muchos autores no se han puesto de acuerdo42, me detendré a dar algunas consideraciones respecto a cómo perfeccionar la labor de la ANPP. Resulta ilógico pensar que un órgano que en la práctica se reúne dos o como máximo tres veces al año, puede realizar un eficaz control de constitucionalidad sobre las disposiciones de otros órganos (Consejo de Estado, Consejo de Ministros, etcétera). Además, resulta cuestionable que sea el propio órgano creador de las leyes, el que controle la constitucionalidad de su decir y de la forma en que lo hace. Aquel se erige en juez de lo que es parte, y aun cuando esta situación se sustenta en la observancia del Principio de Unidad de Poder estimamos que es poco viable.

Por consiguiente se requerirá como parte del fortalecimiento de la ANPP y con vistas a su reestructuración futura, de un órgano legislativo más pequeño en número y de carácter permanente. Así podrá revisar con oportunidad, profundidad y objetividad esas disposiciones inferiores a la ley y su relación con la Constitución. La experiencia nacional ha demostrado que resulta necesaria la permanente operatividad de nuestro máximo órgano de poder, para lograr, de conjunto con otros factores, su plena eficacia dentro del sistema político.

\section{1. ¿Qué ha pasado con las omisiones de legislador?}

La respuesta a la pregunta con la que iniciamos este epígrafe viene a exponer con más claridad lo ineficaz del actual sistema de control de constitucionalidad cubano. Como vimos anteriormente la inconstitucionalidad por omisión ocurre porque no se

41 PÉREZ; PRIETO (Comps.). Op. cit. p. 174-175.

42 Respecto a otros criterios de clasificación sobre el control constitucional en Cuba pueden consultarse varios trabajos de los profesores Julio Fernández Bulté, Marta Prieto Valdés y Lissette Pérez Hernández, referenciados en varios de los trabajos recogidos en MATILLA, Andry y FERRER Eduardo (Coords.). Escritos sobre Derecho Procesal Constitucional. La Habana: Unión Nacional de Juristas de Cuba, 2012. 
legisla, cuando existe un mandato constitucional que dispone se dicte una disposición para determinada cuestión. Básicamente se trata del incumplimiento de un deber estatal, ya sea por el legislativo o el ejecutivo.

Dadas las características del sistema político cubano y ante el no acatamiento de las disposiciones constitucionales por parte del órgano legislativo, específicamente, se ha producido, en algunos casos, la intervención del Partido Comunista de Cuba (PCC). Tal coyuntura genera un fuerte reto para la defensa de los derechos ciudadanos, pues una de las muchas patologías relacionadas con aquellos consiste en la ausencia de leyes de desarrollo.

Cuestiones tan importantes como la regulación de las libertades de palabra y prensa; la relación del Estado con las instituciones religiosas; o los límites que tendrán los derechos durante las situaciones excepcionales, entre otras, han quedado abandonadas en el orden legislativo.

En este sentido, destaca el artículo 53 constitucional donde se recogen las citadas libertades de expresión y de prensa, dejándose a una ley especial la regulación de los mismos sin que esta haya sido aún adoptada43. Al final la temática ha quedado supeditada a la práctica político-partidista, dirigida por el Departamento Ideológico del Comité Central del PCC, y no se ha efectuado el correspondiente control sobre esta inactividad del legislador, generándose un supuesto de inconstitucionalidad por omisión.

Obvio es que esta pasividad del órgano creador de las leyes en Cuba no es controlable. Sencillamente en un contexto donde el control es político y no hay intervención judicial alguna, la ANPP no se cuestionará a sí misma por qué no ha legislado. Al ser juez y parte siempre será de su exclusiva consideración la necesidad y oportunidad de desarrollar en ley los contenidos constitucionales.

Este asunto no es ni por asomo exclusivo del ejemplo comentado con anterioridad, pues se trata más bien de un fenómeno generalizado en el entorno nacional luego de la reforma constitucional de 1992. La Constitución cubana remite a una ley que paute el ejercicio de la libertad de credo y las relaciones entre la iglesia y el Estado, disposición normativa que tampoco se ha adoptado. Ante esta situación, los vínculos entre las organizaciones religiosas y el gobierno cubano han sido conducidos por la Oficina de Asuntos Religiosos del Comité Central del PCC. Una vez más la postura partidista se ha puesto en función de controlar el ejercicio de un derecho reconocido constitucionalmente.

\footnotetext{
43 La necesidad de una ley de prensa como instrumento para definir espacios de poder y modos de actuación en virtud de lo establecido por la Constitución cubana, ha sido un reclamo perenne de los principales estudiosos de la Teoría de la Comunicación nacional. Al respecto GARCÍA, Julio. Revolución, socialismo, periodismo. La Habana: Ed. Pablo de la Torriente, 2013. p. 200 y 201.
} 
Para el caso de la regulación diferenciada de los límites a los derechos durante la ocurrencia de situaciones excepcionales, tampoco se ha legislado en virtud de lo dispuesto por el artículo 67 de la Constitución. En esta materia no se ha producido, al menos directamente, la intervención del PCC, pero resalta el hecho de que la Ley No75, Ley de la Defensa Nacional, no haya pautado nada al respecto; considerando que entre las cuestiones que abarca está la declaración de las situaciones excepcionales, sus efectos y su terminación 44 .

Esta disposición solo se limita a enunciar un catálogo de derechos cuyo ejercicio se afectará mientras dure cualquiera de las mencionadas situaciones, pero no establece nada sobre cuán diferente será dicho ejercicio45. Solo acotar que a nuestro juicio la futura regulación respecto a los límites de los mismos debe ser en base a una ley adoptada por la ANPP y no mediante la intervención del Consejo de Estado, considerando lo que planteamos con anterioridad respecto a los grados de legitimidad de ambos.

Con lo expuesto hasta aquí resulta claro que la ausencia de leyes que instrumenten los derechos antes mencionados, así como sus garantías, se muestra como una de las causas de ineficacia de tales previsiones constitucionales. Por ende, se hace necesaria la intervención legislativa para asegurar la exigibilidad y justiciabilidad de aquellos, frente a cualquier violación de los mismos. Estos aspectos resultan claves para el actual proceso de perfeccionamiento de la institucionalidad nacional, algo que se ha tornado en constante llamado de las principales autoridades políticas del país46.

\section{A MODO DE CONCLUSIONES}

La necesidad de fiscalizar a los órganos de poder en correspondencia con la Constitución y los derechos en ella reconocidos, resulta clave en la construcción de sociedades y sistemas políticos democráticos. Ante las complejidades del mundo contemporáneo este control no debe solo abarcar las actividades del Estado, sino también la inactividad de aquellos órganos que no han cumplido con un deber. Su no hacer también debe ser controlado, extremo en el que solo cabe la intervención de los tribunales. No puede dejarse en manos de quien tiene una obligación de hacer, el incumplimiento o el cumplimiento defectuoso de aquella.

En el caso cubano no es posible controlar la inconstitucionalidad por omisión, considerando que el modelo articulado es de tipo político, o sea, está en manos de la ANPP. Resulta fácilmente comprensible que el órgano legislativo no se cuestionará a sí

44 Artículo 1 de la Ley No75, Ley de la Defensa Nacional. En: PÉREZ; PRIETO (Comps.). Op. cit. p. 127.

45 Artículo 10 de la Ley No75, Ley de la Defensa Nacional. En: PÉREZ; PRIETO (Comps.). Op. cit. p. 133.

46 Baste con señalar las múltiples intervenciones públicas de Raúl Castro Ruz, Presidente de los Consejos de Estado y de Ministros de la República de Cuba, ante la ANPP y otros órganos sobre este tema. Pueden consultarse, por ejemplo, sus discursos ante las sesiones plenarias de la ANPP en los años 2014, 2015 y 2016, divulgadas por la prensa cubana y extranjera. 
mismo ante la inactividad en el acatamiento de un mandato constitucional, máxime cuando sus miembros no son electos dentro de un sistema electoral competitivo. Esto último implica que no hay pugna entre diversas fuerzas políticas, lo cual podría operar como causa motivadora de la producción legislativa. La misma en Cuba depende de prioridades establecidas por los órganos superiores del Estado (ANPP, Consejo de Estado y Consejo de Ministros) en coordinación con el Ministerio de Justicia (MINJUS) y otros organismos de la administración estatal. Lo conflictivo de este mecanismo es que entre las prioridades no ha estado desarrollar contenidos de nuestra máxima ley que reconocen derechos constitucionales. Soy de los que piensa que en política nada es casual, y sostengo la opinión de que no estamos en presencia de meros olvidos legislativos.

Aunque resulta cierto que el PCC no funciona como sujeto electoral, la inobservancia del deber de legislar por parte de la ANPP ha dejado en manos de aquel el establecimiento de ciertas reglas del juego, respecto al ejercicio de al menos dos derechos constitucionales. El fundamento de la intromisión partidista ha recaído en sucesivas interpretaciones, a nuestro juicio erróneas, del artículo 5 de la Constitución que reconoce al PCC como (...) fuerza dirigente superior de la sociedad y el Estado (...)47.

Tal reconocimiento no puede bajo ningún principio anteponerse al deber estatal de regular las cuestiones vinculadas con el adecuado ejercicio de los derechos que la carta magna reconoce a los ciudadanos cubanos. Que la institución partidista actúe de esta forma supone la imposición de directrices, a menudo desconocidas en su contenido y alcance, cuyos efectos abarcan más allá de su militancia política.

A todo lo dicho debe sumarse que tampoco existen mecanismos que permitan a la ciudadanía accionar ante la no actividad legislativa. Por mandato expreso del artículo 657 apartado 4 de la Ley de Procedimiento Civil, Administrativo, Laboral y Económico (LPCALE), las materias constitucionales están excluidas de la jurisdicción administrativa48; y ya sabemos que no se dispone de un proceso constitucional.

Todo el entorno que hemos descrito hasta aquí refleja la escasa aplicabilidad directa de la Constitución cubana. Su eficacia como norma suprema del ordenamiento jurídico se ha vista limitada, entre otros factores, por el no desarrollo de los preceptos que ella contiene. Sin embargo, esta ha sido la práctica política durante más de veinticuatro años contados luego de 1992, sin que se avizore al menos en el futuro cercano un cambio al respecto. Aunque no solo ha ocurrido este fenómeno en materia de derechos constitucionales, la impronta en este aspecto cobra especial relevancia dada la praxis política que se ha seguido. La exclusión de los tribunales como defensores los

\footnotetext{
47 Artículo 5 de la Constitución de la República de Cuba. En: PÉREZ; PRIETO (Comps.). Selección legislativa de Derecho Constitucional Cubano. La Habana: Ed. Félix Varela, 2002. p. 14.

48 ORGANIZACIÓN NACIONAL DE BUFETES COLECTIVOS (ONBC). Ley de Procedimiento Civil, Administrativo, Laboral y Económico, Ley número 7, de 19 de agosto de 1977 (Edición revisada y actualizada). La Habana: Ediciones ONBC, 2012. p. 136.
} 
contenidos de la carta magna nacional; la no instrumentación oportuna de los postulados de la misma; una ANPP de escasa operatividad como órgano de control; y una organización política interventora en el ejercicio de los derechos ciudadanos; ha generado un marco institucional necesario de superar para la democratización del sistema político.

Parafraseando a la profesora cubana Prieto Valdés, si la tutela constitucional es la primera garantía jurídica de los derechos esenciales para el hombre en cada sociedad, el control efectivo de la preservación de esta supremacía constituye la garantía de la garantía ${ }^{49}$. Aceptando esta postura podemos entonces afirmar que el desarrollo en disposiciones especiales de los preceptos constitucionales reconocedores de derechos, cuando estos remitan a aquellas, constituye un factor crucial para tutelar y garantizar lo enunciado por la norma suprema de todo ordenamiento jurídico.

\section{REFERENCIAS}

AHUMADA, María. El control de constitucionalidad de las omisiones legislativas. Revista del Centro de Estudios Constitucionales, Madrid, n. 8, p. 169-194, ene./abr. 1991.

ALVARADO, Adolfo. El debido proceso. En: UNAM. Justicia y Sociedad. México D.F.: Instituto de Investigaciones Jurídicas de la UNAM, 1994.

ARAGÓN, Manuel. Constitución, democracia y control. México D.F.: Instituto de Investigaciones Jurídicas de la Universidad Nacional Autónoma de México (UNAM), 2002.

ARENAS, Marcela. Inconstitucionalidad por omisión legislativa. Contexto colombiano. Revista Diálogos de Derecho y Política, Bogotá, año 6, n. 13, p. 5-24, ene./abr. 2014.

ARMENGOL, Carlos. El Derecho Constitucional del Siglo XXI en Latinoamérica: Un cambio de paradigma. En: VICIANO, Roberto (Edit.). Estudios sobre el nuevo Constitucionalismo Latinoamericano. Valencia: Ed. Tirant Lo Blanch, España, 2012.

BIDART, Germán J. La justicia constitucional y la inconstitucionalidad por omisión. Anuario Jurídico UNAM, México D.F., v. 6, p. 9-18, 1979.

BLUME, E. La reforma del Tribunal Constitucional peruano. In: VEGA GÓMEZ, Juan; CORZO SOSA, Egar (Coords.). Tribunales y Justicia Constitucional: Memorias del VII Congreso Iberoamericano de Derecho Constitucional. México D.F.: Instituto de Investigaciones Jurídicas de la UNAM, 2002.

BREWER, Allan. La elección popular indirecta de altos funcionarios del Estado en Venezuela y su violación por el Estado autoritario: el golpe de Estado de diciembre de 2014 dado con las

49 PRIETO, Marta. Las garantías constitucionales de los derechos fundamentales y la Constitución cubana de 1976. En: MATILLA, Andry (Coord.). La Constitución cubana de 1976: cuarenta años de vigencia. La Habana: Ed. UNIJURIS, 2016. p. 176. 
inconstitucionales designaciones de los titulares de las ramas del Poder Público. Revista de Investigações Constitucionais, Curitiba, vol. 2, n. 2, p. 63-92, maio/ago. 2015.

CARBONELL, Miguel (Coord.). En busca de las normas ausentes. Ensayos sobre la inconstitucionalidad por omisión. México D.F.: Instituto de Investigaciones Jurídicas de la UNAM, 2003.

COLECTIVO de Autores. Temas de Derecho Administrativo Cubano. La Habana: Ed. Félix Varela, 2006.

DELGADO, Yanelys; DEL RíO, Mirta A. La democracia socialista en la Constitución de 1976. En: MATILLA, Andry (Coord.). La Constitución cubana de 1976: cuarenta años de vigencia. La Habana: Ed. UNIJURIS, 2016.

FERNÁNDEZ, Julio . Aproximación a la constitucionalidad por omisión. En: CARBONELL, Miguel (Coord.). En busca de las normas ausentes. Ensayos sobre la inconstitucionalidad por omisión. México D.F.: Instituto de Investigaciones Jurídicas de la UNAM, 2003.

FERNÁNDEZ, Julio. Los modelos de control constitucional y la perspectiva de Cuba hoy. En: PÉREZ, Lissette; PRIETO, Marta (Comps.). Temas de derecho constitucional cubano. La Habana: Ed. Félix Varela, 2004.

FERNÁNDEZ, Serafín S. Cuba y el Control Constitucional en el Estado Socialista de Derecho: Reflexiones para su perfeccionamiento. En: MATILLA, Andry (Comp.). Estudios cubanos sobre control de constitucionalidad (1901-2008). México D.F.: Ed. Porrua, 2009.

FERRER, Eduardo et al. (Coords.). Diccionario de Derecho Procesal Constitucional y Convencional. Tomos I y II. México D.F.: Instituto de Investigaciones Jurídicas de la UNAM, 2014.

FIX, Héctor. Breves reflexiones sobre la naturaleza, estructura y funciones de los organismos jurisdiccionales especializados en la resolución de procesos constitucionales. In: VEGA GÓMEZ, Juan; CORZO SOSA, Egar (Coords.). Tribunales y Justicia Constitucional: Memorias del VII Congreso Iberoamericano de Derecho Constitucional. México D.F.: Instituto de Investigaciones Jurídicas de la UNAM, 2002.

GARCÍA, Julio. Revolución, socialismo, periodismo. La Habana: Ed. Pablo de la Torriente, 2013.

GARZÓN, Edgard F. La inconstitucionalidad por omisión: una revisión jurídica. Revista Dixi 20, Bogotá, vol. 16, n. 20, p. 29-36, dic. 2014.

KELSEN, Hans. Teoría pura del Derecho. Madrid: Ed. Tecnos, 1995.

LEAL, Salvador. Inconstitucionalidad por omisión. Revista Cuestiones Políticas, Maracaibo, vol. 18, n. 18, p. 53-67, jun. 2002.

LOEWENSTEIN, Karl. Teoría de la Constitución. Barcelona: Ed. Ariel, 1982.

LOEWENSTEIN, Karl. La garantía jurisdiccional de la Constitución. La justicia constitucional. México D.F.: Universidad Nacional Autónoma de México, 2001. 
MATILLA, Andry; FERRER Eduardo (Coords.). Escritos sobre Derecho Procesal Constitucional. La Habana: Unión Nacional de Juristas de Cuba, 2012.

MATILLA, Andry. Comentarios sobre las fuentes del Derecho administrativo cubano (excepto el reglamento). In: Temas de Derecho Administrativo Cubano. La Habana: Ed. Félix Varela, 2006.

MATILLA, Andry (Comp.). Estudios cubanos sobre control de constitucionalidad (1901-2008). México D.F.: Ed. Porrua, 2009.

MATILLA, Andry (Coord.). La Constitución cubana de 1976: cuarenta años de vigencia. La Habana: Ed. UNIJURIS, 2016.

MIRANDA, Jorge. Manual de direito constitucional. Vol. II. Coímbra: Ed. Coímbra, 1993.

NOGUEIRA, Humberto. Consideraciones sobre las sentencias de los tribunales constitucionales y sus efectos en América del Sur. Revista lus et Praxis, Santiago de Chile, vol. 10, n. 1, p. 113-158, 2004.

NOGUERA, Albert. Los derechos sociales en las nuevas constituciones latinoamericanas. Valencia: Ed. Tirant lo Blanch, 2010.

PERAZA, José. Derecho Constitucional General y Comparado. La Habana: Ed. Félix Varela, 2002.

PÉREZ, Lissette; PRIETO, Marta. El control de la constitucionalidad de las leyes y otros actos. Sus formas en Estados Unidos y Cuba. En: PÉREZ, Lissette; PRIETO, Marta (Comps.). Temas de derecho constitucional cubano. La Habana: Ed. Félix Varela, 2004.

PÉREZ, Lissette; PRIETO, Marta (Comps.). Temas de derecho constitucional cubano. La Habana: Ed. Félix Varela, 2004.

PÉREZ, Lissette; PRIETO, Marta (Comps.). Selección legislativa de Derecho Constitucional Cubano. La Habana: Ed. Félix Varela, 2002.

PÉREZ, Javier. Inconstitucionalidad por Omisión. Temas Básicos de Derecho Constitucional. Vol. 3. Madrid: Ed. Civitas, 2001.

PRIETO, Marta. Las garantías constitucionales de los derechos fundamentales y la Constitución cubana de 1976. En: MATILLA, Andry (Coord.). La Constitución cubana de 1976: cuarenta años de vigencia. La Habana: Ed. UNIJURIS, 2016.

PRIETO, Marta. Reflexiones en torno al carácter normativo de la Constitución. In: PÉREZ; PRIETO (Comps.). Temas de derecho constitucional cubano. La Habana: Ed. Félix Varela, 2004.

RODRIGUES, Márcia. Inconstitucionalidade por omissão. Revista da Procuradoria Geral do Estado de São Paulo, São Paulo, vol. 18, n. 30, jul./dez. 1988.

RODRÍGUEZ, Yumil. Algunas consideraciones sobre la supremacía de la Constitución y el control de constitucionalidad como medio de hacerla efectiva. MATILLA, Andry; FERRER Eduardo 
(Coords.). Escritos sobre Derecho Procesal Constitucional. La Habana: Unión Nacional de Juristas de Cuba, 2012.

ROJAS, Sandra. Inconstitucionalidad por omisión en Colombia. Revista Estudios de Derecho, Bogotá, año LXII, vol. LIX, n.133-134, jul./dic. 2000.

RUIZ, Ricardo. Crítica a la llamada inconstitucionalidad por omisión. Revista Iberoamericana de Derecho Procesal Constitucional, Ciudad de México, n. 2, jul./dic. 2004.

SAGÜÉS, Néstor. Problemas constitucionales en la solución de la inconstitucionalidad por omisión. Cuadernos Constitucionales de la Cátedra Fadrique Furió Ceriol, Rosario, n. 58-59, p. 253-264, 2007.

SILVA, Alfonso da. Aplicabilidad de las normas constitucionales. México D.F.: Instituto de Investigaciones Jurídicas de la UNAM, 2003.

SIMÓN, Liana. El control de constitucionalidad de las leyes en Cuba: el reto de su judicialización. En: MATILLA, Andry; FERRER Eduardo (Coords.). Escritos sobre Derecho Procesal Constitucional. La Habana: Unión Nacional de Juristas de Cuba, 2012.

UNAM. Justicia y Sociedad. México D.F.: Instituto de Investigaciones Jurídicas de la UNAM, 1994. VALDÉS, E.; PARDO, O. Los sistemas de control constitucional frente a los derechos fundamentales en Colombia, Cuba y España. Revista UIS-Humanidades, Bucaramanga vol. 28, n. 1, ene./jun. 1999.

VICIANO, Roberto; MARTíNEZ, Rubén. Fundamentos teóricos del nuevo constitucionalismo latinoamericano. En: VICIANO, Roberto (Edit.). Estudios sobre el nuevo Constitucionalismo Latinoamericano. Valencia: Ed. Tirant Lo Blanch, España, 2012.

VILLABELLA, Carlos. Las formas de gobierno en el mundo. Un estudio desde el derecho constitucional comparado de Europa, América Latina y el Caribe. Puebla: Instituto de Ciencias Jurídicas de la Universidad de Puebla, 2008. 